Journal of Engineering and Applied Sciences 14 (Special Issue 9): 10638-10641, 2019

ISSN: 1816-949X

(C) Medwell Journals, 2019

\title{
Measurement of Natural Radioactivity in Some Marble Samples by using (HPGe) Detector
}

\author{
Hasan Mohammed Abdullah \\ Ibn Hayyan University College, Holy Karbala, Iraq
}

\begin{abstract}
In this study, measurement of specific activity concentrations in ten commercial marble samples from different countries were carried out by using (HPGe) system. The results of measurements have shown that the maximum values specific activity concentrations for ${ }^{238} \mathrm{U},{ }^{232} \mathrm{Th}$ which were equal to 27.420 , $30.480 \mathrm{~Bq} / \mathrm{kg}$, respectively, Brazilian origin while the maximum values specific activity concentrations for ${ }^{40} \mathrm{~K}$ which were equal to $297.210 \mathrm{~Bq} / \mathrm{kg}$ Iranian origin which were less than the corresponding recommended global values reported by UNSCEAR, publication. The radiation hazard indices $\left[\mathrm{Ra}_{\mathrm{eq}}, \mathrm{D}_{\mathrm{y}},(\mathrm{AED})_{\mathrm{in}},(\mathrm{AED})_{\mathrm{out}}, \mathrm{H}_{\mathrm{in}}, \mathrm{H}_{\mathrm{ex}}\right.$ and $\mathrm{I}_{\mathrm{\gamma}}$ ] were also studied. The obtained results were also found to be less than the allowed limits given by UNSCEAR. Thus, all results obtained in the present work have shown no significant radiological hazard when the studied marble is used, for example, for construction of flooring buildings.
\end{abstract}

$\underline{\text { Key words: Radiation hazard indices, marble samples, (HPGe) system, present work, significant, construction }}$

\section{INTRODUCTION}

It is well known that the traces of radionuclides are found in soil, water, air and human bodies, we inhale and ingest radionuclides every day of our lives and radioactive materials have been ubiquitous on Earth, since, its creation. The presence of natural radioactivity in soil results in internal and external exposure to humans. Radioactive nuclides which can be found in nature are generally categorized in two distinct families, namely of arising from either origin. The most commonly encountered radionuclides that irradiate the human body through external exposure (primarily by gamma radiation) are U-235, U-238 and Th-232 and their subsequent radioactive decay products and K-40 (UNEP., 1985), Nuclei can undergo a variety of processes which result in the emission of radiation. The most common forms of nuclear radiation are beta particles, alpha and gamma-rays, our bodies contain radioactive materials such as C-14 and K-40 (Cameron and Skofronick, 1992). The flooring materials (marble, granite, etc.) are a part of building materials that contain several amounts of natural radioactive elements. Materials obtain from rock and soil have mainly natural radionuclides of the Th-232 and U-238 chains and the radioactive isotope of K-40 (Sahin et al., 2017).

\section{MATERIALS AND METHODS}

Ten marble material's samples were collected from different markets and factories. The samples were chosen in terms of the widely and most common type Iraqi markets (Fig. 1). All the sampleswere pulverized into small pieces, then into fine powder by using jaw crusher

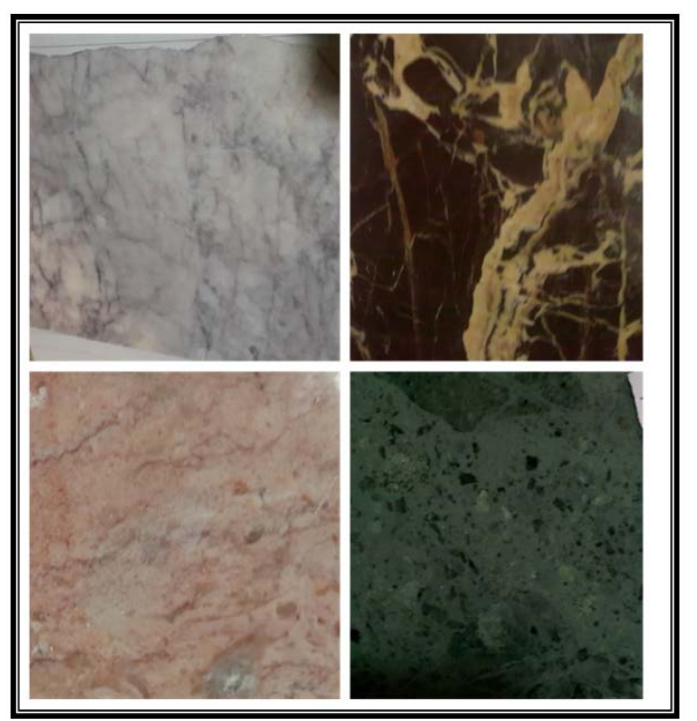

Fig. 1: Marble samples

(Fig. 2a). The samples were dried at $80^{\circ} \mathrm{C}$ for $2 \mathrm{~h}$ to ensure that any moisture was removed from the samples and then to obtain uniform particle sizes, a $600 \mu \mathrm{m}$ mesh was used to sieve the samples after that samples were weighted ( $1 \mathrm{~kg})$ and transferred to a Marinelli beaker $(1 \mathrm{~L})$. In the present work a $(3 \times 3)$ inch $(\mathrm{HPGe})$ system (Fig. 2b).

An essential requirement for the measurement of gamma emitter is the exact identity of photo peaks presents in the spectrum produced by the detector system. The energy calibration was performed by using a standard source of 1 L capacity of Marinelli beaker of Eu-152, which has been prepared in this research with energies 

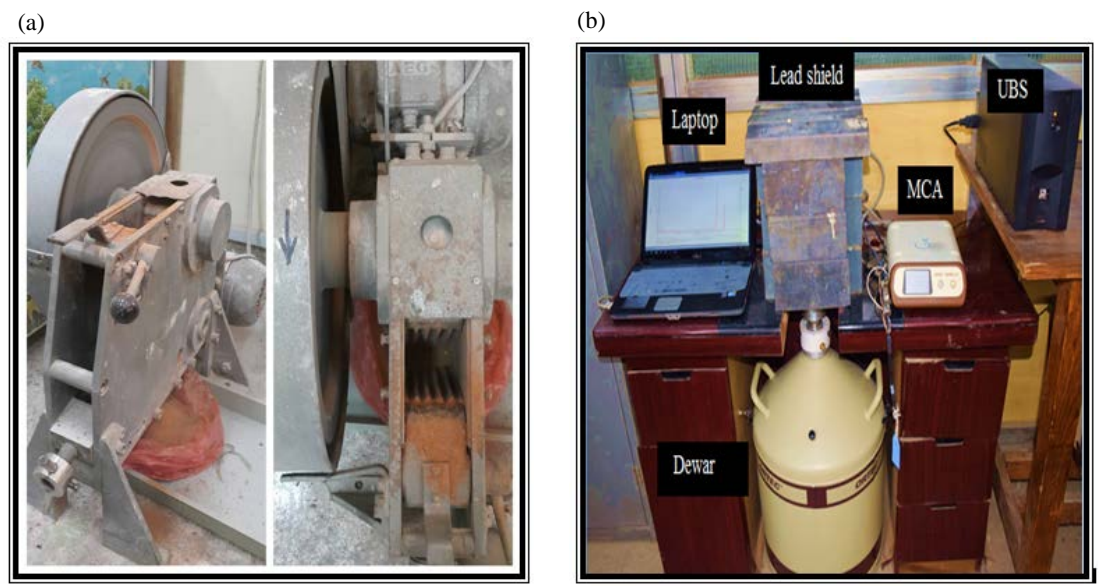

Fig. 2(a, b): (a) Jaw crusher and (b) (HPGe) system

(411.1, 1408.0, 344.3, 964.0, 444.6, 778.9, 1112.0, 121.8, 1085.8 and $244.7 \mathrm{keV}$ ). The energy calibration source should be counted long enough to produce well-defined photo peaks.

\section{Determination of some gamma radiation parameters (radiation hazard indicies)}

Activity concentration: The specific activity concentrations of radionuclides in marble samples were obtained by using Eq. 1 (Diab et al., 2008):

$$
\mathrm{A}=\frac{\mathrm{N}-\mathrm{BG}}{\mathrm{T} \cdot \mathrm{I}_{\gamma}\left(\mathrm{E}_{\gamma}\right) \cdot \varepsilon\left(\mathrm{E}_{\gamma}\right) \cdot \mathrm{M}}
$$

Where:

A : The specific activity of radioactive elements measured

BG : The net peak area of the background

$\left(E_{\gamma}\right)$ : The detector efficiency at Energy $\left(E_{\gamma}\right)$

$\mathrm{I}_{\gamma}\left(\mathrm{E}_{\gamma}\right)$ : The abundance at Energy $\left(\mathrm{E}_{\gamma}\right)$

$\mathrm{M}$ : The mass of the soil sample

$\mathrm{T}$ : The measured time which is equal (3600 sec)

Radium equivalent ( $\mathrm{Ra}_{\mathrm{eq}}$ (Diab et al., 2008):

$$
\mathrm{Ra}_{\text {eq }}=1.43 \mathrm{~A}_{\mathrm{Th}}+\mathrm{A}_{\mathrm{U}}+0.077 \mathrm{~A}_{\mathrm{K}}
$$

Where, $A_{U}, A_{T h}, A_{k}$ activity concentration of a series of thorium and potassium and uranium, respectively.

Absorbed Dose rate $\left(D_{\gamma)}\right.$ (Shawkat, 2000):

$$
\mathrm{D}_{\gamma}=0.604 \mathrm{~A}_{\mathrm{Th}}+0.0417 \mathrm{~A}_{\mathrm{K}}+0.462 \mathrm{~A}_{\mathrm{U}}
$$

The Annual Effective Dose (AED ${ }_{\text {in }}$, AED $_{\text {out }}$ (El Arabi, 2005):

$$
(\mathrm{AED})_{\mathrm{in}}=\mathrm{D}_{\gamma}(\mathrm{nGy} / \mathrm{h}) \times 10^{-6} \times 8760 \mathrm{~h} / \mathrm{y} \times(0.7 \mathrm{~Sv} / \mathrm{Gy}) \times 0.80
$$

$$
(\mathrm{AED})_{\text {out }}=\mathrm{D}_{\gamma}(\mathrm{nGy} / \mathrm{h}) \times 10^{-6} \times 8760 \mathrm{~h} / \mathrm{y} \times(0.7 \mathrm{~Sv} / \mathrm{Gy}) \times 0.20
$$

Internal and external Hazard index $\left(\mathrm{H}_{\mathrm{in}}, \mathrm{H}_{\mathrm{ex}}\right)$ (El-Taher and Makhluf, 2010):

$$
\begin{aligned}
& \mathrm{H}_{\text {in }}=\frac{\mathrm{A}_{\text {Th }}}{259}+\frac{\mathrm{A}_{\mathrm{U}}}{185}+\frac{\mathrm{A}_{\mathrm{K}}}{4810} \leq 1 \\
& \mathrm{H}_{\text {ex }}=\frac{\mathrm{A}_{\text {Th }}}{259}+\frac{\mathrm{A}_{\mathrm{U}}}{370}+\frac{\mathrm{A}_{\mathrm{K}}}{4810} \leq 1
\end{aligned}
$$

Activity concentration Index $\left(\mathrm{I}_{\gamma}\right)$ :

$$
I_{\gamma}=\frac{A_{\text {Th }}}{200}+\frac{A_{U h}}{300}+\frac{A_{K}}{300}
$$

\section{RESULTS AND DISCUSSION}

The results of the present work were summarized in Table 1 from which it can be noticed that, the maximum value of specific activity of ${ }^{238} U$ in the studied samples was found inmarble sample of Brazilian origin which was equal to $27.420 \mathrm{~Bq} / \mathrm{kg}$ while the minimum value of specific activity of ${ }^{238} \mathrm{U}$ was found in marble sample of Iraqi origin which was equal to $14.340 \mathrm{~Bq} / \mathrm{kg}$. The present results have shown that values of specific activity for ${ }^{238} \mathrm{U}$ in all studied samples were less than the recommended value of $35 \mathrm{~Bq} / \mathrm{kg}$ for the specific activity of ${ }^{238} \mathrm{U}$ (UNSCEAR, 2000).

The maximum value of specific activity of ${ }^{232} \mathrm{Th}$ in the studied samples was found in marble sample of Brazilian origin which was equal to $30.480 \mathrm{~Bq} / \mathrm{kg}$ while the minimum value of specific activity of ${ }^{232} \mathrm{Th}$ was found in marble sample of Iranian origin which was equal to $18.510 \mathrm{~Bq} / \mathrm{kg}$. The present results have shown that values of specific activity for ${ }^{232} \mathrm{Th}$ in all studied samples were less than the recommended value of $30 \mathrm{~Bq} / \mathrm{kg}$ for the specific activity of ${ }^{232} \mathrm{Th}$ (UNSCEAR, 2000). 
J. Eng. Applied Sci., 14 (Special Issue 9): 10638-10641, 2019

Table 1: Specific activities of radionuclides with significant radiological hazard for all marble samples

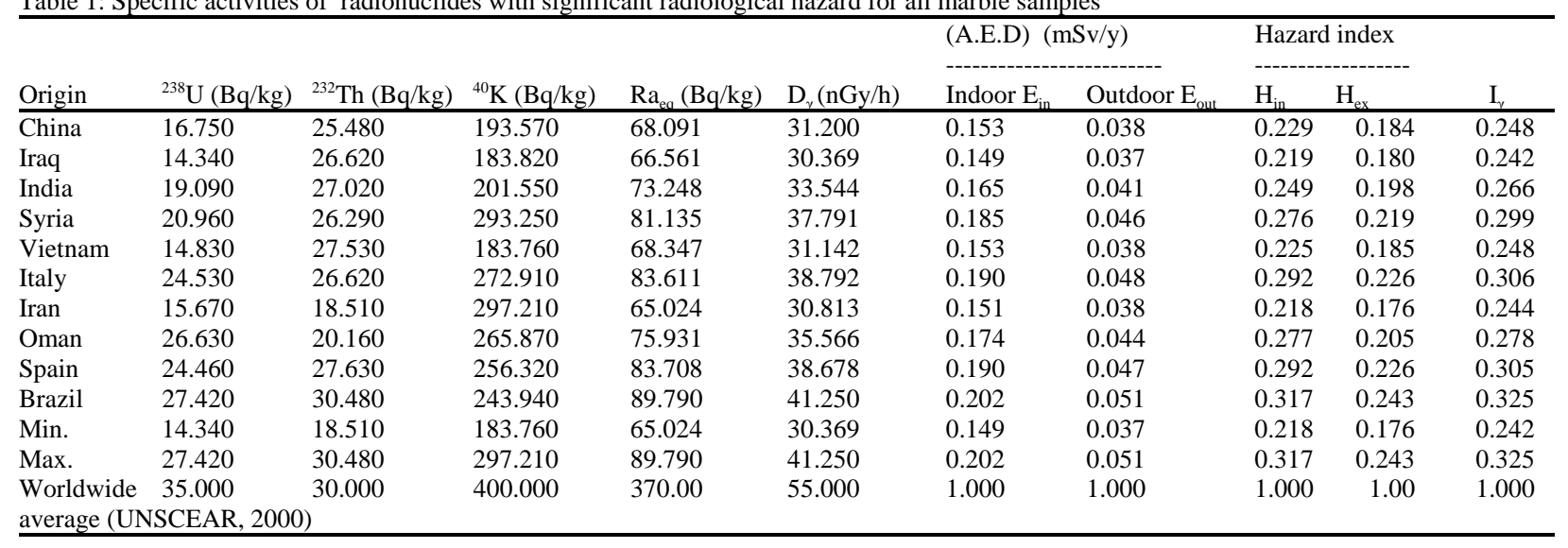

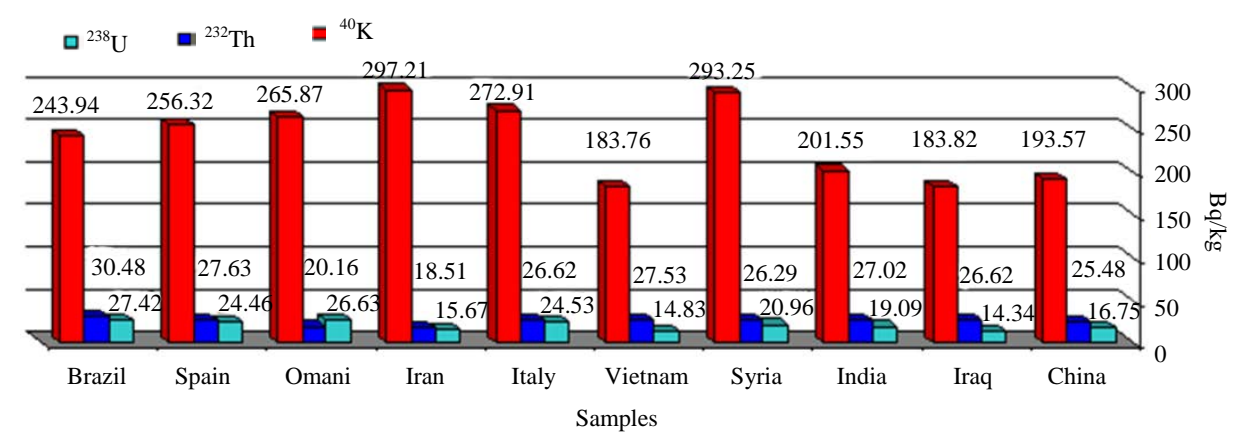

Fig. 3: Specific activity of ${ }^{238} \mathrm{U},{ }^{232} \mathrm{Th}$ and ${ }^{40} \mathrm{~K}$ in all marble samples

The maximum value of specific activity of ${ }^{40} \mathrm{~K}$ in the studied samples was found in marble sample of Iranian origin which was equal to $297.210 \mathrm{~Bq} / \mathrm{kg}$ while the minimumvalue of specific activity of ${ }^{40} \mathrm{~K}$ was found in marble sample of Vietnamese origin which was equal to $183.760 \mathrm{~Bq} / \mathrm{kg}$ with . The present results have shown that values of specific activity for ${ }^{40} \mathrm{~K}$ in all studied samples were less than the recommended value of $400 \mathrm{~Bq} / \mathrm{kg}$ for the specific activity of ${ }^{40} \mathrm{~K}$ (UNSCEAR, 2000) (Fig. 3).

The maximum value of $\mathrm{Ra}_{\mathrm{eq}}$ in the studied samples was found in marble sample of Brazilian origin which was equal to $89.790 \mathrm{~Bq} / \mathrm{kg}$ while the minimum value of $\mathrm{Ra}_{\text {eq }}$ was found in marble sample of Iranian origin which was equal to $65.024 \mathrm{~Bq} / \mathrm{kg}$. The present results have shown that values of $\mathrm{Ra}_{\mathrm{eq}}$ in all studied samples were less than the recommended value of $370 \mathrm{~Bq} / \mathrm{kg}$ for the $\left(\mathrm{Ra}_{\mathrm{eq}}\right)$ (UNSCEAR, 2000).

The maximum value of $\left(D_{\gamma}\right)$ in the studied samples was found in marble sample of Brazilian origin which was equal to $41.250 \mathrm{nGy} / \mathrm{h}$ while the minimum value of $\mathrm{D}_{\gamma}$ was found in marble sample of Iraqi origin which was equal to $30.369 \mathrm{nGy} / \mathrm{h}$. The present results have shown that values of $\mathrm{D}_{\gamma}$ rate in all studied samples were less than the recommended value of $55 \mathrm{nGy} / \mathrm{h}$ for the $\left(D_{\gamma}\right)$ (UNSCEAR, 2000).
The maximum value of $\mathrm{AED}_{\text {in }}$ in the studied samples was found in marble sample of Brazilian origin which was equal to $0.202 \mathrm{mSv} / \mathrm{y}$ while the minimumvalue of $\mathrm{AED}_{\text {in }}$ was found in marble sample of Iraqi origin which was equal to $0.149 \mathrm{mSv} / \mathrm{y}$. The present results have shown that values of $A E D_{\text {in }}$ in all studied samples were less than there commended value of $1 \mathrm{mSv} / \mathrm{y}$ for the $(A E D)_{\text {in }}$ (UNSCEAR, 2000).

The maximum value of $\mathrm{AED}_{\text {out }}$ in the studied samples was found in marble sample of Brazilian origin which was equal to $0.051 \mathrm{mSv} / \mathrm{y}$ while the minimum value of $\mathrm{AED}_{\text {out }}$ was found in marble sample Iraqi of origin which was equal to $0.037 \mathrm{mSv} / \mathrm{y}$. The present results have shown that values of $\mathrm{AED}_{\text {out }}$ in all studied samples were less than there commended value of $1 \mathrm{mSv} / \mathrm{y}$ for the outdoor annual effective dose equivalent (UNSCEAR, 2000).

The maximum value of $\mathrm{H}_{\mathrm{in}}$ in the studied samples was found in marble sample of Brazilian origin which was equal to 0.317 while the minimum value of $\mathrm{H}_{\text {in }}$ was found in marble sample Iranian origin which was equal to 0.218 with an average value of $0.249 \pm 0.014$. The present results have shown that values of $\mathrm{H}_{\text {in }}$ in all studied samples were less than the recommended value of 1 for the $\left(\mathrm{H}_{\text {in }}\right)$ (UNSCEAR, 2000).

The maximum value of $\mathrm{H}_{\mathrm{ex}}$ in the studied samples was found in marble sample of Brazilian origin which was equal to 0.243 while the minimum value of $\mathrm{H}_{\mathrm{ex}}$ was found in marble sample Iranian origin which was equal to 0.176. 
The present results have shown that values of $\mathrm{H}_{\mathrm{ex}}$ in all studied samples were less than the recommended value of 1 for the $\left(\mathrm{H}_{\mathrm{ex}}\right)$ (UNSCEAR, 2000).

The maximum value of $\mathrm{I}_{\gamma}$ inthe studied samples was found in marble sample of Brazilian origin which was equal to $0.325 \mathrm{mSv} / \mathrm{y}$ while the minimum value of $\mathrm{I}_{\gamma}$ was found in marble sample of Iraqi origin which was equal to $0.242 \mathrm{mSv} / \mathrm{y}$. The present results have shown that values of $\mathrm{I}_{\gamma}$ in all studied samples were less than the recommended value of 1 for $\mathrm{I}_{\gamma}$ (UNSCEAR, 2000).

The results of marble revealed the most samples have low specific activity concentration due to absence of minerals containing radioactivity but these results vary according to different origins of marbles because a marble is a metamorphic rock and different by the presence of minerals and location.

\section{CONCLUSION}

The results of the present work concerning values of the specific activity for ${ }^{232} \mathrm{Th},{ }^{40} \mathrm{~K}$ and ${ }^{238} \mathrm{U}$ and determination the parameters $\left[\operatorname{Ra}_{\mathrm{eq}}, \mathrm{D}_{\gamma},(\mathrm{AED})_{\mathrm{in}},(\mathrm{AED})_{\text {out, }}\right.$ $\mathrm{H}_{\mathrm{in}}, \mathrm{H}_{\mathrm{ex}}$ and $\mathrm{I}_{\gamma}$, all were found to be lower than their corresponding allowed limits and hence will pose relatively none series health risk.

\section{REFERENCES}

Cameron, J.R. and J.G. Skofronick, 1992. Medical Physics: Physics of the Body. Medical Physics Publishing Corporation, Wisconsin, USA., ISBN-13: 9780944838242, Pages: 343.
Diab, H.M., S.A. Nouh, A. Hamdy and S.A. El-Fiki, 2008. Evaluation of natural radioactivity in a cultivated area around a fertilizer factory. J. Nucl. Radiat. Phys., 3: 53-62.

El Arabi, A.M., 2005. Gamma activity in some environmental samples in South Egypt. Indian J. Pure Applied Phys., 43: 422-426.

El-Taher, A. and S. Makhluf, 2010. Natural radioactivity levels in phosphate fertilize $r$ and its environmental implications in Assuit governorate, Upper Egypt. Indian J. Pure Applied Phys., 48: 697-702.

Sahin, L., N. Hafizoglu, H. Cetinkaya, K. Manisa, E.Bozkurt and A. Bicer, 2017. Assessment of radiological hazard parameters due to natural radioactivity in soils from granite-rich regions in Kutahya Province, Turkey. Isot. Environ. Health Stud., 53: 212-221.

Shawkat, N., 2000. Radioactive pollution and environmental sources in the province of Nineveh. Master Thesis, University of Wasit, Kut, Iraq.

UNEP., 1985. Radiation Doses, Effects, Risks. United Nations Environment Programme, Nairobi, Kenya, ISBN-13: 9789280711042, Pages: 64.

UNSCEAR, 2000. Effects and Risks of Ionizing Radiations. United Nations Scientific Committee on the Effects of Ionizing Radiation, New York. 